\title{
Healthcare-associated pneumonia among hospitalized patients in a Korean tertiary hospital
}

Ji Ye Jung, Moo Suk Park, Young Sam Kim, Byung Hoon Park, Se Kyu Kim, Joon Chang, Young Ae Kang*

\begin{abstract}
Background: Healthcare-associated pneumonia (HCAP) has more similarities to nosocomial pneumonia than to community-acquired pneumonia (CAP). However, there have only been a few epidemiological studies of HCAP in South Korea. We aimed to determine the differences between HCAP and CAP in terms of clinical features, pathogens, and outcomes, and to clarify approaches for initial antibiotic management.

Methods: We conducted a retrospective, observational study of 527 patients with HCAP or CAP who were hospitalized at Severance Hospital in South Korea between January and December 2008.

Results: Of these patients, 231 (43.8\%) had HCAP, and 296 (56.2\%) had CAP. Potentially drug-resistant (PDR) bacteria were more frequently isolated in HCAP than CAP (12.6\% vs. 4.7\%; $P=0.001)$, especially in the low-risk group of the PSI classes (41.2\% vs. 13.9\%; $P=0.027$ ). In-hospital mortality was higher for HCAP than CAP patients ( $28.1 \%$ vs. $10.8 \%, P<0.001)$, especially in the low-risk group of PSI classes $(16.4 \%$ vs. $3.1 \% ; P=0.001)$. Moreover, tube feeding and prior hospitalization with antibiotic treatment within 90 days of pneumonia onset were significant risk factors for PDR pathogens, with odds ratios of $14.94(95 \% \mathrm{Cl} 4.62-48.31 ; P<0.001)$ and $2.68(95 \% \mathrm{Cl}$ 1.32-5.46; $P=0.007$ ), respectively.
\end{abstract}

Conclusions: For HCAP patients with different backgrounds, various pathogens and antibiotic resistance of should be considered, and careful selection of patients requiring broad-spectrum antibiotics is important when physicians start initial antibiotic treatments.

\section{Background}

Pneumonia has traditionally been classified as either community- or hospital- acquired, based on the patient's location when the infection was acquired. However, an increasing number of out-of-hospital services, such as nursing homes, outpatient parenteral therapy, hemodialysis clinics, and domiciliary care, create a class of patients who do not truly reside in the "community."

Previous studies have suggested that nursing homeacquired pneumonia or pneumonia in long-term care facilities should be considered separately from community-acquired pneumonia (CAP) [1-3]. Infections occurring in these patients show a more similar epidemiological pattern to hospital-acquired pneumonia (HAP) than to CAP [1-3]. Different epidemiological patterns from CAP require a distinct targeted therapeutic approach, especially

\footnotetext{
* Correspondence: mdkang@yuhs.ac
Division of Pulmonology and Critical Care Medicine, Department of Internal

* Correspondence: mdkang@yuhs.ac
Division of Pulmonology and Critical Care Medicine, Department of Internal Medicine, Institute of Chest Disease, Yonsei University College of Medicine, Seoul, Republic of Korea
}

(c) 2011 Jung et al; licensee BioMed Central Ltd. This is an Open Access article distributed under the terms of the Creative Commons Attribution License (http://creativecommons.org/licenses/by/2.0), which permits unrestricted use, distribution, and reproduction in any medium, provided the original work is properly cited. 2000, the newly published CAP guidelines have recommended management specific to this type of pneumonia, and considered it to be a separate entity from CAP [6-8].

In 2005, the American Thoracic Society (ATS)/Infectious Diseases Society of America (IDSA) documented healthcare-associated pneumonia (HCAP) as a new category of pneumonia [9]. However, only a few studies on HCAP have included patients who met the criteria of the 2005 ATS/IDSA guidelines [10]. Previous HCAP studies have revealed a diverse composition of participants because this new HCAP category includes various criteria for heterogeneous conditions, such as nursing home residence, previous antibiotic therapy, or regular attendance at a dialysis clinic [11-13]. Since the criteria for defining HCAP have not been standardized between these studies, and due to the existence of geographically different etiologies, more data are required for a better characterization of unified HCAP and for redefining HCAP. 
In South Korea, there are limited data and no therapeutic guidelines focusing on HCAP [14]. Considering the relatively small proportion of long-term care facilities and the different antibiotic resistance patterns of the microorganisms in CAP, the clinical composition, causative pathogens, and clinical outcomes of HCAP in South Korea could be different from those in other countries. Therefore, a study evaluating HCAP characteristics and clinical outcomes in South Korea is needed.

The aim of this study was to categorize patients according to the 2005 ATS/IDSA guidelines, to determine differences in baseline characteristics, pathogens, and clinical outcomes between patients with HCAP and CAP in a university teaching hospital in South Korea, and to clarify approaches for initial antibiotic management.

\section{Methods \\ Study design and subjects}

We conducted a retrospective observational study of 527 patients with CAP or HCAP who were hospitalized at Severance Hospital (a 2,000-bed university tertiary referral hospital in Seoul, South Korea) between January 1 and December 31, 2008. Patients were classified into either a CAP or HCAP group, according to the 2005 ATS/IDSA guidelines. We compared baseline characteristics, and identified pathogens, antibiotics regimens, and clinical outcomes between the two groups. The study protocol was approved by the Ethical Review Committee of Severance Hospital.

\section{Definitions}

Pneumonia was defined as the presence of a new infiltrate on the chest radiography plus at least one of the following: fever (temperature $\geq 38.0^{\circ} \mathrm{C}$ ) or hypothermia (temperature $<35.0^{\circ} \mathrm{C}$ ), new cough with or without sputum production, pleuritic chest pain, dyspnea, or altered breath sounds on auscultation [15].

HCAP included any patient who fulfilled any of the following: (1) hospitalization in an acute care hospital for two or more days within 90 days of the infection; (2) residence in a nursing home or long-term care facility; (3) infusion therapy, such as intravenous antibiotic therapy, chemotherapy or wound care, within 30 days of a current infection; (4) regular attendance at a dialysis clinic, including hemodialysis and peritoneal dialysis [9]. CAP included any patient with pneumonia who did not meet the HCAP criteria.

Patients were defined as being immunosuppressed if they fulfilled at least one of the following criteria: (1) daily administration of systemic corticosteroids (at least $15 \mathrm{mg}$ of prednisone per day for more than one month or combination therapy with low dose corticosteroids and other immunosuppressants including azathioprine, mycophenolate, methotrexate, cyclosporine, or cyclophosphamide) (2) seropositivity for human immunodeficiency virus; (3) receipt of either a solid organ or bone marrow transplant; (4) treatment with radiation therapy or chemotherapy for an underlying malignancy during the 6 months prior to hospital admission; or (5) underlying acquired immune deficiency disorder $[11,13]$.

In this study, potentially drug resistant (PDR) pathogens included methicillin-resistant Staphylococcus aureus (MRSA), Pseudomonas aeruginosa, Acinetobacter baumannii, Stenotrophomonas maltophilia, and extended spectrum $\beta$-lactamase (ESBL)-producing Enterobacteriaceae, based on previous reports showing problematic clinical outcomes for infections caused by these pathogens $[16,17]$.

Inappropriate antibiotic therapy was defined as when any initially prescribed antibiotics were not active against the identified pathogens, based on in vitro susceptibility testing $[10,12]$.

The definition of early treatment failure was clinical deterioration within 72 hours of starting treatment, such as a lack of response or worsening of fever, respiratory condition, and/or radiographic status, requiring mechanical ventilation or aggressive fluid resuscitation or vasopressors, or death $[12,18,19]$.

The severity of pneumonia was evaluated and categorized using the validated prediction rule and pneumonia severity index (PSI) scores: low, class I to III; intermediate, class IV; high, class V [20,21].

\section{Antibiotic treatment}

Antibiotic therapy was initiated in basic accordance with the ATS/IDSA guidelines $(8,9)$, but the detailed antibiotic regimen complied with the attending physician's choice taking into consideration patient risk factors and the severity of the disease. Empirical antibiotic therapy was modulated after the pathogen was identified according to the susceptibility test. However, the antibiotic therapy was changed or extended according to the attending physician's decision for patients in whom the pathogen was not identified or whose clinical condition deteriorated.

\section{Microbiological studies}

Pathogens in samples obtained from sputum, blood, or other samples were investigated using standard microbiological procedures. Blood cultures were accepted as an etiological diagnosis if no other source could be identified for the positive blood culture. Sputum samples were cultured in a semi-quantitative manner, and an etiological diagnosis was established when a predominant microorganism was isolated from group 4 or 5 sputum, according to Murray and Washington's grading system [22]. A rapid immunochromatographic assay was 
used for detecting the Streptococcus pneumoniae antigen (BinaxNOW ${ }^{\circledR}$ S. pneumoniae Test; Binax Inc., Scarborough, ME, USA) and Legionella pneumophila serogroup I antigen (BinaxNOW ${ }^{\mathbb{B}}$ Legionella Test; Binax Inc., Scarborough, ME, USA) in urine. Antibodies against atypical pathogens (Mycoplasma pneumoniae) were detected by microparticle agglutination assay (MAG). Cases that did not meet any of these criteria were considered to be pneumonia of unknown etiology. The antibiotic sensitivity of all isolates was determined using a disc diffusion method, according to the Clinical and Laboratory Standards Institute guidelines [23].

\section{Statistical analyses}

Categorical variables were analyzed using the $\chi^{2}$ test or Fisher's exact test, and continuous variables were analyzed using Student's $t$-test or Mann-Whitney U test. After testing the distribution of continuous variables, normally distributed variables were presented as mean \pm standard deviation (SD) and non-normally distributed variables were presented as median (interquartile range, [IQRs]). Multivariate analysis was performed using a logistic regression model to estimate risk factors for occurrence of PDR pathogens, which was presented with the odds ratio (OR, 95\% confidence intervals, CI). Potential candidate variables were those with $P<0.05$ in univariate analyses, and the multi-collinearity of variables was checked. All tests were two-sided and a $P$-value $<0.05$ was deemed to be statistically significant. SPSS 18.0 (SPSS, Chicago, IL, USA) was used for all statistical analyses.

\section{Results}

\section{Patient characteristics}

Of the 527 patients, 231 (43.8\%) were classified as HCAP and 296 (56.2\%) as CAP. The baseline and clinical characteristics of the patients with HCAP and CAP are shown in Table 1 . Of the 231 HCAP patients, 170 (73.6\%) had been hospitalized for two or more days within 90 days of pneumonia, 150 (64.9\%) received intravenous antibiotic therapy/chemotherapy/wound care within 30 days of pneumonia onset, 24 (10.4\%) attended a hemodialysis clinic, and $21(9.1 \%)$ resided in a nursing home or extended care facility (data not shown).

\section{Pathogen distribution}

Table 2 shows the distribution of causative organisms. The numbers of sputum samples evaluated for pathogens were $203(87.9 \%)$ in HCAP patients and 266 (89.9\%) in CAP patients, and those of blood samples were 230 (99.6\%) in HCAP patients and 289 (97.6\%) in CAP patients (data not shown). An etiological diagnosis was established in 79 HCAP (34.2\%) and 83 CAP patients $(29.1 \%)(P=0.206)$. S. pneumoniae was the most frequently isolated pathogen in CAP patients, while Klebsiella pneumoniae was most frequently isolated in HCAP patients. More PDR pathogens were observed in patients with HCAP.

\section{Antibiotic treatment and clinical outcomes}

Initial antibiotic treatments and outcomes for patients with HCAP and CAP are shown in Table 3. Inappropriate antibiotic therapy tended to be administered more frequently to HCAP patients than CAP patients, although the difference was not significant. Patients in both groups received combination therapy more than monotherapy. The in-hospital mortality and early treatment failure rates were significantly higher in HCAP patients than CAP patients. Patients with HCAP stayed in the hospital longer and showed a more frequent need for mechanical ventilation than patients with CAP.

\section{Occurrence of PDR pathogens and clinical outcomes and in each severity class assessed by PSI}

Table 4 shows the occurrence of PDR pathogens, early treatment failure, and mortality in each risk class. In low-risk patients, HCAP showed a higher occurrence of PDR pathogens $(41.2 \%$ vs. $13.9 \% ; P=0.027)$ and early treatment failure $(16.4 \%$ vs. $6.3 \% ; P=0.024)$. Moreover, patients with HCAP showed higher in-hospital mortality than those with CAP in the low $(16.4 \%$ vs. $3.1 \% ; P=$ $0.001)$ and intermediate $(25.2 \%$ vs. $14.1 \% ; P=0.044)$ risk classes.

\section{Risk Factors for Occurrence of PDR Pathogens}

The multivariate analysis of risk factors for the occurrence of PDR pathogens are shown in Table 5. Tube feeding and previous hospitalization within 90 days of pneumonia onset were significant risk factors; the corresponding odds ratios were 14.94 and 2.68. Of 162 patients with identified pathogens, 57 patients (35.2\%) had been previously hospitalized within 90 days of infection. However, when previous hospitalization was classified into two different risk factors in relation to antibiotic treatment, 36 patients $(63.2 \%)$ had previously been hospitalized with antibiotic treatment and 21 patients $(36.8 \%)$ had been hospitalized without. The former was a significant risk factor (odds ratio $=2.45 ; 95 \%$ CI 1.19-5.02; $P=0.014$ ), but the latter was not (odds ratio $=1.59 ; 95 \%$ CI $0.54-4.69 ; P=0.398)($ data not shown).

\section{Discussion}

This study showed that half of the hospitalized patients with pneumonia in a university tertiary referral hospital in South Korea were diagnosed with HCAP, and identified differences in comorbidities, pathogens, initial 
Table 1 Baseline Characteristics of Patients with HCAP and CAP ${ }^{a}$

\begin{tabular}{|c|c|c|c|}
\hline Baseline Characteristics & $\operatorname{HCAP}(n=231)$ & $\begin{array}{c}\text { CAP } \\
(n=296)\end{array}$ & $P$-value \\
\hline Age (year) & $63.5 \pm 13.1$ & $65.4 \pm 15.7$ & 0.148 \\
\hline Male & $162(70.1)$ & $194(65.5)$ & 0.264 \\
\hline Female & $69(29.9)$ & $102(34.5)$ & \\
\hline \multicolumn{4}{|l|}{ Underlying diseases } \\
\hline Diabetes Mellitus & $52(22.5)$ & 59 (19.9) & 0.471 \\
\hline Chronic lung disease ${ }^{\mathrm{b}}$ & $22(9.5)$ & $56(18.9)$ & 0.003 \\
\hline Central nervous system disorders & $26(11.3)$ & $47(15.9)$ & 0.127 \\
\hline Renal disease & $31(13.4)$ & $27(9.1)$ & 0.118 \\
\hline Hypertension & $93(40.3)$ & $125(42.2)$ & 0.649 \\
\hline Cardiovascular disease & $19(8.2)$ & $62(20.9)$ & $<0.001$ \\
\hline Liver disease & $12(5.2)$ & $16(5.4)$ & 0.915 \\
\hline Rheumatologic disease & $9(3.9)$ & $18(6.1)$ & 0.259 \\
\hline Malignancy & $156(67.5)$ & $58(19.6)$ & $<0.001$ \\
\hline Solid organ malignancy & $133(57.6)$ & $42(14.2)$ & $<0.001$ \\
\hline Hematologic malignancy & $26(11.3)$ & $17(5.7)$ & 0.022 \\
\hline \multicolumn{4}{|l|}{ Clinical parameters } \\
\hline Confusion & $35(15.2)$ & $34(11.5)$ & 0.216 \\
\hline Septic shock at onset & $57(24.7)$ & $46(15.5)$ & 0.009 \\
\hline $\mathrm{PaO}_{2}<60 \mathrm{mmHg}, \mathrm{SpO}_{2}<90 \%$, or $\mathrm{PaO}_{2} / \mathrm{FiO} 2<300$ & 79 (34.2) & $96(32.4)$ & 0.669 \\
\hline Pleural effusion & $43(18.6)$ & $49(16.6)$ & 0.536 \\
\hline Acute renal failure at onset & $32(13.9)$ & $37(12.5)$ & 0.648 \\
\hline \multicolumn{4}{|l|}{ Laboratory findings } \\
\hline $\mathrm{pH}<7.35$ & $10(4.3)$ & $23(7.8)$ & 0.106 \\
\hline Hematocrit $<30 \%$ & $87(37.7)$ & $51(17.2)$ & $<0.001$ \\
\hline Glucose $>250 \mathrm{mg} / \mathrm{dL}$ & $20(8.7)$ & $21(7.1)$ & 0.506 \\
\hline Blood urea nitrogen $>30 \mathrm{mg} / \mathrm{dL}$ & $67(29.0)$ & 49 (16.6) & 0.001 \\
\hline Leukocytes $\left(\times 10^{3} / \mu \mathrm{l}\right)$ & $12790 \pm 13603$ & $13175 \pm 7519$ & 0.700 \\
\hline C-reactive protein (mg/dL) & $15.4 \pm 11.2$ & $13.1 \pm 10.0$ & 0.017 \\
\hline Erythrocyte Sedimentation Rate (mm) & $83.2 \pm 33.8$ & $71.4 \pm 35.7$ & $<0.001$ \\
\hline $\begin{array}{l}\text { Eastern Cooperative Oncology } \\
\text { Group (ECOG) }\end{array}$ & $1.7 \pm 0.9$ & $1.2 \pm 0.9$ & $<0.001$ \\
\hline Prior antibiotics use & $97(42.0)$ & $6(1.0)$ & $<0.001$ \\
\hline Immunosuppressed $^{c}$ & $142(61.5)$ & $39(13.2)$ & $<0.001$ \\
\hline Pneumonia Severity Index Risk Classes & $113.7 \pm 32.3$ & $92.2 \pm 33.6$ & $<0.001$ \\
\hline Low (I-III) & $55(23.8)$ & $159(53.7)$ & \\
\hline Intermediate (IV) & $115(49.8)$ & 99 (33.4) & $<0.001$ \\
\hline $\operatorname{High}(V)$ & $61(26.4)$ & $38(12.8)$ & \\
\hline
\end{tabular}

a Data are presented as numbers (percentages) unless otherwise indicated. Plus-minus values are means \pm standard deviation.

${ }^{b}$ Chronic lung disease includes asthma, COPD, and structural lung diseases, such as bronchiectasis and interstitial lung disease.

c Immunosuppression includes the following: (1) daily administration of systemic corticosteroids (at least $15 \mathrm{mg}$ of prednisone per day for more than one month or combination therapy with low dose corticosteroids and other immunosuppressants including azathioprine, mycophenolate, methotrexate, cyclosporine, or cyclophosphamide); (2) seropositivity for human immunodeficiency virus; (3) received either a solid organ transplant or bone marrow transplant; (4) treated with radiation therapy or chemotherapy for an underlying malignancy during the 6 months prior to hospital admission; (5) an underlying acquired immune deficiency disorder.

HCAP healthcare-associated pneumonia.

CAP community-acquired pneumonia.

antibiotic regimens, and clinical outcomes between the HCAP and CAP groups. Moreover, tube feeding and prior hospitalization with antibiotic treatment within 90 days of pneumonia were found to be significant risk factors for PDR pathogens.
Patients with HCAP were more frequently classified into the intermediate- and high-risk classes than patients with CAP. More PDR pathogens were identified, more inappropriate antibiotic treatments were initiated, and clinical outcomes were worse for HCAP 
Table 2 Pathogen Distribution in Patients with HCAP and CAP $^{\mathrm{a}}$

\begin{tabular}{|c|c|c|c|}
\hline Microbes & $\begin{array}{c}\text { HCAP } \\
(n=231)\end{array}$ & $\begin{array}{c}\text { CAP } \\
(n=296)\end{array}$ & $P$-value \\
\hline Pathogen identified & $79(34.2)$ & $83(29.1)$ & 0.206 \\
\hline Gram-positive pathogens & $34(14.7)$ & $54(18.2)$ & 0.282 \\
\hline MRSA & $9(3.9)$ & $6(2.0)$ & \\
\hline MSSA & $4(1.7)$ & $9(3.0)$ & \\
\hline Streptococcus pneumoniae & $11(4.8)$ & $33(11.1)$ & \\
\hline Streptococcus other & $4(1.7)$ & $3(1.0)$ & \\
\hline Enterococcus species & $0(0)$ & $1(0.3)$ & \\
\hline Others $^{b}$ & $6(2.6)$ & $3(1.0)$ & \\
\hline Gram-negative pathogens & $46(19.9)$ & $28(9.5)$ & 0.001 \\
\hline Pseudomonas aeruginosa & $10(4.3)$ & $5(1.7)$ & \\
\hline Escherichia coli & $1(0.4)$ & $0(0)$ & \\
\hline Haemophilus influenzae & $2(0.9)$ & $3(1.0)$ & \\
\hline Klebsiella pneumoniae & $23(10.0)$ & $13(4.4)$ & \\
\hline ESBL producing ${ }^{c}$ & 9/23 (39.1) & $3 / 13(23.1)$ & \\
\hline Enterobacter species & $4(1.7)$ & $1(0.3)$ & \\
\hline Acinetobacter baumannii & $1(0.4)$ & $0(0)$ & \\
\hline Stenotrophomonas maltophilia & $1(0.4)$ & $1(0.3)$ & \\
\hline Others $^{d}$ & $4(1.7)$ & $5(1.7)$ & \\
\hline Anaerobes $^{e}$ & $1(0.4)$ & $0(0)$ & \\
\hline Atypical pathogens ${ }^{f}$ & $0(0)$ & $3(1.0)$ & \\
\hline Fungal pathogens ${ }^{9}$ & $1(0.4)$ & $1(0.3)$ & \\
\hline PDR pathogens & 29 (12.6) & $14(4.7)$ & 0.001 \\
\hline
\end{tabular}

${ }^{a}$ Data are presented as numbers (percentages) unless otherwise indicated.

${ }^{\mathrm{b}}$ Coagulase-negative Staphylococci species.

c Number of patients/total number of patients in whom Klebsiella pneumonia was identified (percentages).

${ }^{\mathrm{d}}$ Moraxella catarrhalis (1 in HCAP and 3 in CAP), Serratia marcescens (2 in HCAP and 2 in CAP), Citrobacter freundii (1 in HCAP).

${ }^{\mathrm{e}}$ Bacteroides fragilis.

${ }^{r}$ Mycoplasma pneumonia (3 in CAP).

${ }^{g}$ Aspergillus species.

HCAP healthcare-associated pneumonia.

CAP community-acquired pneumonia.

MRSA methicillin-resistant Staphylococcus aureus.

MSSA methicillin-sensitive Staphylococcus aureus.

ESBL extended-spectrum $\beta$-lactamase.

PDR potentially drug-resistant.

patients, especially those in the low and intermediate risk classes. The results of this study were consistent with those of previous studies reporting distinct clinical characteristics of HCAP and worse outcomes than CAP $[10,12,14,24]$. However, the baseline characteristics and the backgrounds of patients with HCAP differed slightly from previous reports. In this study, more patients with HCAP had malignancies (67.5\%) and an immunosuppressive condition (61.5\%) as comorbidity than other studies ( $14.2 \%$ to $22.3 \%)$ $[12,24]$. Furthermore, the HCAP group included a relatively lower proportion of patients residing in nursing homes or extended care facilities (9.1\%) than previous reports $(28.0 \%$ to $61.0 \%)[12,24]$. These differences
Table 3 Antibiotic Treatments and Clinical Outcomes in Patients with HCAP and CAP ${ }^{a}$

\begin{tabular}{|c|c|c|c|}
\hline Treatment & $\begin{array}{c}\text { HCAP } \\
(n=231)\end{array}$ & $\begin{array}{c}\text { CAP } \\
(n=296)\end{array}$ & $P$-value \\
\hline Inappropriate antibiotic therapy ${ }^{b}$ & $\begin{array}{l}27 / 73 \\
(37.0)\end{array}$ & $\begin{array}{l}19 / 78 \\
(24.4)\end{array}$ & 0.092 \\
\hline Monotherapy & $30(13.0)$ & $53(17.9)$ & 0.124 \\
\hline Amino-penicillins & $3(1.3)$ & $5(1.7)$ & - \\
\hline Cephalosporin & $5(2.2)$ & $8(2.7)$ & - \\
\hline Antipseudomonal penicillins & $6(2.6)$ & $6(2.0)$ & - \\
\hline Fluroquinolone & $13(5.6)$ & $34(11.5)$ & - \\
\hline Carbapenem & $3(1.3)$ & $0(0)$ & - \\
\hline Combination therapy & $201(87.0)$ & $243(82.1)$ & 0.124 \\
\hline$\beta$-lactams + fluoroquinolone & $4(1.7)$ & $8(2.7)$ & - \\
\hline$\beta$-lactams + macrolide & $36(15.6)$ & $112(37.8)$ & $<0.001$ \\
\hline$\beta$-lactams + clindamycin & $10(4.3)$ & $14(4.7)$ & - \\
\hline$\beta$-lactams + aminoglycoside & $6(2.6)$ & $1(0.3)$ & - \\
\hline $\begin{array}{l}\text { Fluoroquinolone }+ \\
\text { Clindamycin }\end{array}$ & $13(5.6)$ & $12(4.1)$ & - \\
\hline $\begin{array}{l}\text { Antipseudomonal } \beta \text {-lactams }+ \\
\text { fluroquinolone }\end{array}$ & $63(27.3)$ & $48(16.2)$ & 0.001 \\
\hline $\begin{array}{l}\text { Antipseudomonal } \beta \text {-lactams }+ \\
\text { macrolide }\end{array}$ & $0(0)$ & $1(0.3)$ & - \\
\hline $\begin{array}{l}\text { Antipseudomonal } \beta \text {-lactams }+ \\
\text { clindamycin }\end{array}$ & $6(2.6)$ & $3(1.0)$ & - \\
\hline $\begin{array}{l}\text { Antipseudomonal } \beta \text {-lactams + } \\
\text { aminoglycoside }\end{array}$ & $8(3.5)$ & $2(0.7)$ & - \\
\hline Other combination therapy ${ }^{c}$ & $55(23.8)$ & $42(14.2)$ & 0.002 \\
\hline \multicolumn{4}{|l|}{ Clinical outcomes } \\
\hline In-hospital mortality & $65(28.1)$ & $32(10.8)$ & $<0.001$ \\
\hline Early treatment failure $^{d}$ & $56(24.2)$ & $37(12.5)$ & $<0.001$ \\
\hline ICU admission & $49(21.2)$ & $37(12.5)$ & 0.007 \\
\hline ICU mortality & $31(13.4)$ & $21(7.1)$ & 0.016 \\
\hline $\begin{array}{l}\text { Need for mechanical } \\
\text { ventilation }\end{array}$ & $47(20.3)$ & $39(13.2)$ & 0.027 \\
\hline Duration of hospital stay (days) & $18.6 \pm 19.1$ & $12.9 \pm 13.1$ & $<0.001$ \\
\hline
\end{tabular}

${ }^{a}$ Data are presented as numbers (percentages) unless otherwise indicated. Plus-minus values are means \pm standard deviation.

${ }^{b}$ Number of patients/total number of patients whose causative pathogens and antibiotic sensitivity test results are known (percentages). Results of antibiotics sensitivity test were not available in six patients with HCAP and five patients with CAP.

c Others contain combination therapy of three or more drugs, including aminopenicillins, cephalosporin, antipseudomonal penicillin, aminglycoside, macrolide, clindamycin, fluoroquinolone, glycopeptide, trimethoprim/ sulfamethoxazole, and antifungal agent.

d Early treatment failure was defined as clinical deterioration within $72 \mathrm{~h}$ of treatment such as lack of response or worsening of fever, respiratory condition, and/or radiographic status requiring mechanical ventilation, aggressive fluid resuscitation or vasopressors, or death.

HCAP healthcare-associated pneumonia.

CAP community-acquired pneumonia.

ICU intensive care unit.

indicate the heterogeneous aspect of HCAP and the difficulty of establishing one unified approach for patients with HCAP [25].

Despite the high rate of anti-pseudomonal therapy in HCAP patients, a high proportion of inappropriate initial 
antibiotics were given to the patients in this study (37.0\%), as compared with the studies of Shindo et al. (20.8\%), Carratalà et al. (5.6\%), and Park et al. (24.6\%) $[10,12,14]$. This is likely due to the higher rate of PDR pathogen infection (36.7\%), as compared with the aforementioned reports of Shindo et al. (22.1\%), Carratalà et al. (3.5\%), and Park et al. (29.3\%) in HCAP patients, and the relatively high proportion of ESBL-producing Gram-negative pathogens $[10,12,14]$. In this study, $K$. pneumoniae $(10.0 \%)$ was the most common pathogen in patients with HCAP, followed by $S$. aureus (5.6\%), $S$. pneumoniae (4.8\%), and P. aeruginosa (4.3\%) in that order. In addition, the rate of ESBL-producing $K$. pneumoniae was relatively high in our study. This may be explained by differences in the underlying comorbidities of HCAP patients and their reasons for being in contact with the healthcare environment. A large proportion of patients with malignancies who had been regularly hospitalized for anti-cancer chemotherapy and a considerable proportion of patients with recent antibiotic therapy $(42.0 \%)$ could explain an increasing colonization of ESBL-producing K. pneumoniae. In a report by Park et al., another study done in a tertiary hospital of South Korea, $K$. pneumoniae is also the second most common pathogen of HCAP and the rate of ESBL-producing K. pneumoniae comes to $79 \%$ in both CAP and HCAP [14]. Thus, efforts to identify the pathogens and to adjust empirical antibiotics accordingly, based on microbiological data, are more useful than automatic treatment with anti-pseudomonal broad-spectrum antibiotics.

Negative clinical outcomes, including early treatment failure and in-hospital mortality were all higher in HCAP patients than CAP patients. The differences were significant, especially among the low-risk class, and the occurrence of PDR pathogens was also more frequently observed in HCAP patients than in CAP patients among the low-risk class. These results were similar to the study of Shindo et al. in Japan, which showed higher mortality and PDR pathogens occurrence in HCAP patients than in CAP patients in the moderate severity class according to the A-DROP (age, dehydration, respiratory failure, orientation disturbance, and low blood pressure) scoring system [12]. In patients classified as high-risk, mortality was not different between HCAP and CAP patients, probably due to the severity of the illness itself, regardless of the presence of PDR pathogens. The poorer outcomes for patients with HCAP than for those with CAP in the low-risk class might be explained by the higher rate of early treatment failure $(16.4 \%$ vs. $6.3 \% ; P=0.024)$, associated with a higher proportion of PDR pathogen $(41.2 \%$ vs. $13.9 \%$; $P=0.027$ ), as shown in Table 4 .

Although we could not find a significant difference in the rate of inappropriate initial antibiotics treatment
Table 4 Occurrence of PDR Pathogens and Clinical Outcomes and in Each Severity Class Assessed by the Pneumonia Severity Index in Patients

\begin{tabular}{|c|c|c|c|}
\hline $\begin{array}{l}\text { Pneumonia Severity Index } \\
\text { Classes }\end{array}$ & $\begin{array}{c}\text { HCAP } \\
(n=231)\end{array}$ & $\begin{array}{c}\text { CAP } \\
(n=296)\end{array}$ & $P$-value \\
\hline \multicolumn{4}{|l|}{ PDR pathogens ${ }^{a}$} \\
\hline Low (I-III) & $7 / 17(41.2)$ & 5/36 (13.9) & 0.027 \\
\hline Intermediate (IV) & $14 / 40(35.0)$ & $5 / 29(17.2)$ & 0.103 \\
\hline $\operatorname{High}(\mathrm{V})$ & $8 / 22(36.4)$ & $4 / 18(22.2)$ & 0.332 \\
\hline \multicolumn{4}{|l|}{ Early treatment failure ${ }^{b}$} \\
\hline Low (I-III) & 9/55 (16.4) & 10/159 (6.3) & 0.024 \\
\hline Intermediate (IV) & 21/115 (18.3) & 18/99 (18.2) & 0.988 \\
\hline High (V) & $26 / 61(42.6)$ & 9/38 (23.7) & 0.055 \\
\hline \multicolumn{4}{|l|}{ In-hospital mortality ${ }^{b}$} \\
\hline Low (I-III) & 9/55 (16.4) & $5 / 159(3.1)$ & 0.001 \\
\hline Intermediate (IV) & 29/115 (25.2) & 14/99 (14.1) & 0.044 \\
\hline $\operatorname{High}(V)$ & 27/61 (44.3) & 13/38 (34.2) & 0.322 \\
\hline
\end{tabular}

${ }^{a}$ Number of patients/total number of patients whose causative pathogens were identified in each pneumonia severity index class (percentages).

b Data are presented as number of patients/total number of patients in each pneumonia severity index class (percentages).

HCAP healthcare-associated pneumonia.

CAP community-acquired pneumonia.

PDR potentially drug-resistant.

between patients with HCAP and CAP, the proportion of inappropriate antibiotic treatment was significantly higher in HCAP patients infected with PDR pathogen than in those without $(58.6 \%$ vs. $22.7 \% ; P=0.002)$ (data not shown), which is consistent with previous reports $[14,26]$. Therefore, it is important to identify risk factors for PDR pathogens in patients with HCAP to decide who should receive broad-spectrum antibiotics. These efforts would improve clinical outcomes and prevent the emergence of multi-drug resistant microorganisms from overuse of broad-spectrum antibiotics. According to multivariate analysis, significant risk factors for PDR pathogens included the use of antibiotics for more than two days during a

Table 5 Multivariate Analysis of Risk Factors for Occurrence of PDR Pathogens

\begin{tabular}{lccc}
\hline Risk Factors & $\begin{array}{c}\text { Odds } \\
\text { Ratio }\end{array}$ & 95\% Cl & P-value \\
\hline Gender, female & 1.50 & $0.75-3.01$ & 0.256 \\
Age & 1.00 & $0.98-1.02$ & 0.964 \\
Tube feeding & 14.94 & $4.62-48.31$ & $<0.001$ \\
Residence in a nursing home or & 1.90 & $0.53-6.86$ & 0.327 \\
extended care facility & & & \\
Intravenous chemotherapy within 30 days & 0.62 & $0.22-1.77$ & 0.373 \\
Attended a hemodialysis clinic & 2.81 & $0.86-9.19$ & 0.087 \\
Hospitalized in an acute care hospital for & 2.68 & $1.32-5.46$ & 0.007 \\
two or more days within 90 days of the & & & \\
infection & & &
\end{tabular}

PDR potentially drug-resistant.

$\mathrm{Cl}$ confidential interval. 
prior hospitalization within 90 days of pneumonia onset as well as tube feeding. Thus, we suggest that physicians consider broad-spectrum antibiotics for treatment of HCAP patients with these risk factors for PDR pathogens.

HCAP is a newly defined group since 2005 and has been composed of heterogeneous patients with various severities of illness and different reasons for contact with the healthcare environment. Thus, there is little detailed data on these various HCAP groups, though it is associated with significant mortality and high health care costs $[27,28]$. This study may provide useful guidance in understanding the characteristics of HCAP and in developing therapeutic approaches for patients with HCAP in South Korea.

To fully appreciate our results, we should consider the limitations of the present study. First, this was a retrospective study in a single institution with a relatively short duration and may not represent South Korean medical institutions in general. However, this study shows the general characteristics of pneumonia patients admitted to tertiary hospitals in South Korea. Second, the etiology of pneumonia was identified in a low proportion of patients. Thus, the true incidence of PDR pathogen and its effects on the clinical outcomes could have been underestimated. However, $89 \%$ and $99 \%$ of the patients were evaluated using their sputum and blood samples, and our successful pathogen identification rate of $30 \%$ was not relatively low compared to the rate of $20-50 \%$ from previous prospectively designed studies [10,29,30]. Third, atypical pathogens could not be fully evaluated due to inadequate information in the medical records. Fourth, prior antibiotic use could not be fully estimated due to insufficient information from other clinics in the medical records.

\section{Conclusions}

In summary, half of the hospitalized with pneumonia in a university tertiary referral hospital were diagnosed with HCAP. Patients with HCAP showed a higher occurrence of PDR pathogens, more frequent early treatment failure, and a higher mortality rate than patients with CAP, especially in patients with low-risk class. Those HCAP patients who underwent tube feeding and those who have been hospitalized and given antibiotic treatment within the previous 90 days should be mainly considered for broad-spectrum antibiotics.

\section{Abbreviations}

HCAP: healthcare-associated pneumonia; CAP: community acquired pneumonia; PDR: potentially drug-resistant; PSI: pneumonia severity index; ATS: American Thoracic Society.
IDSA: Infectious Diseases Society of America; MRSA: methicillin-resistant Staphylococcus aureus; ESBL: extended spectrum $\beta$-lactamase; MAG: microparticle agglutination assay

SD: standard deviation; Cl: confidence intervals; ICU: intensive care unit

\section{Acknowledgements}

The authors are indebted to all who participated in this study. Thanks to all the health care professionals of the Severance Hospital, and specifically those from the pulmonology units and the emergency room.

\section{Authors' contributions}

JJ carried out screening and acquisition of data, statistical analysis and participated in the writing of the manuscript. MP and YK carried out acquisition of data and statistical analysis. BP and SK participated in the study design and the analysis and interpretation of data. JC participated in the study design, analysis and interpretation of data and critical revision of the manuscript for important intellectual content. YK participated in the study design, analysis and interpretation of data and the writing of the manuscript. All authors have read and approved the final manuscript.

\section{Competing interests}

The authors declare that they have no competing interests.

Received: 4 November 2010 Accepted: 11 March 2011

Published: 11 March 2011

\section{References}

1. Mylotte JM: Nursing home-acquired pneumonia. Clinical Infectious Diseases 2002, 35(10):1205-1211.

2. Muder RR: Pneumonia in residents of long-term care facilities: epidemiology, etiology, management, and prevention. American Journal of Medicine 1998, 105(4):319-330.

3. Zimmer JG, Hall WJ: Nursing home-acquired pneumonia: avoiding the hospital. Journal of the American Geriatrics Society 1997, 45(3):380-381.

4. Friedman ND, Kaye KS, Stout JE, McGarry SA, Trivette SL, Briggs JP, Lamm W, Clark C, MacFarquhar J, Walton AL, Reller LB, Sexton DJ: Health care-associated bloodstream infections in adults: a reason to change the accepted definition of community-acquired infections. Annals of Internal Medicine 2002, 137(10):791-797.

5. Brito V, Niederman MS: Healthcare-associated pneumonia is a heterogeneous disease, and all patients do not need the same broadspectrum antibiotic therapy as complex nosocomial pneumonia. Current opinion in infectious diseases 2009, 22(3):316-325.

6. Mandell LA, Marrie TJ, Grossman RF, Chow AW, Hyland RH: Canadian guidelines for the initial management of community-acquired pneumonia: an evidence-based update by the Canadian Infectious Diseases Society and the Canadian Thoracic Society. The Canadian Community-Acquired Pneumonia Working Group. Clinical Infectious Diseases 2000, 31(2):383-421.

7. Mandell LA, Bartlett JG, Dowell SF, File TM, Musher DM, Whitney C: Update of practice guidelines for the management of community-acquired pneumonia in immunocompetent adults. Clinical Infectious Diseases 2003, 37(11):1405-1433.

8. Niederman MS, Mandell LA, Anzueto A, Bass JB, Broughton WA, Campbell GD, Dean N, File T, Fine MJ, Gross PA, Martinez F, Marrie TJ, Plouffe JF, Ramirez J, Sarosi GA, Torres A, Wilson R, Yu VL: Guidelines for the management of adults with community-acquired pneumonia. Diagnosis, assessment of severity, antimicrobial therapy, and prevention. American Journal of Respiratory and Critical Care Medicine 2001, 163(7):1730-1754

9. American Thoracic Society/Infectious Diseases Society of America: Guidelines for the management of adults with hospital-acquired, ventilator-associated, and healthcare-associated pneumonia. American Journal of Respiratory and Critical Care Medicine 2005, 171(4):388-416.

10. Carratal J, Mykietiuk A, Fernndez-Sab N, Surez C, Dorca J, Verdaguer R, Manresa F, Gudiol F: Health care-associated pneumonia requiring hospital admission: epidemiology, antibiotic therapy, and clinical outcomes. Archives of Internal Medicine 2007, 167(13):1393-1399.

11. Micek ST, Kollef KE, Reichley RM, Roubinian N, Kollef MH: Health careassociated pneumonia and community-acquired pneumonia: a single- 
center experience. Antimicrobial Agents and Chemotherapy 2007, 51(10):3568-3573.

12. Shindo Y, Sato S, Maruyama E, Ohashi T, Ogawa M, Hashimoto N, Imaizumi K, Sato T, Hasegawa Y: Health-care-associated pneumonia among hospitalized patients in a Japanese community hospital. Chest 2009, 135(3):633-640

13. Shorr AF, Zilberberg MD, Micek ST, Kollef MH: Prediction of infection due to antibiotic-resistant bacteria by select risk factors for health careassociated pneumonia. Archives of Internal Medicine 2008, 168(20):2205-2210.

14. Park HK, Song JU, Um SW, Koh WJ, Suh GY, Chung MP, Kim H, Kwon OJ, Jeon K: Clinical characteristics of health care-associated pneumonia in a Korean teaching hospital. Respiratory Medicine 2010, 104(11):1729-1735.

15. Carratal J, Fernndez-Sab N, Ortega L, Castellsagu X, Rosn B, Dorca J, Fernndez-Agera A, Verdaguer R, Martnez J, Manresa F, Gudiol F: Outpatient care compared with hospitalization for community-acquired pneumonia: a randomized trial in low-risk patients. Annals of Internal Medicine 2005, 142(3):165-172.

16. Trouillet JL, Chastre J, Vuagnat A, Joly-Guillou ML, Combaux D, Dombret MC, Gibert C: Ventilator-associated pneumonia caused by potentially drug-resistant bacteria. American Journal of Respiratory and Critical Care Medicine 1998, 157(2):531-539.

17. Bradford PA: Extended-spectrum beta-lactamases in the 21st century: characterization, epidemiology, and detection of this important resistance threat. Clinical Microbiology Reviews 2001, 14(4):933-951, table of contents.

18. Menndez R, Cavalcanti M, Reyes S, Mensa J, Martinez R, Marcos MA, Filella $X$, Niederman $M$, Torres A: Markers of treatment failure in hospitalised community acquired pneumonia. Thorax 2008, 63(5):447-452.

19. Rosn B, Carratal J, Fernndez-Sab N, Tubau F, Manresa F, Gudiol F: Causes and factors associated with early failure in hospitalized patients with community-acquired pneumonia. Archives of Internal Medicine 2004, 164(5):502-508.

20. Fine MJ, Auble TE, Yealy DM, Hanusa BH, Weissfeld LA, Singer DE, Coley CM, Marrie TJ, Kapoor WN: A prediction rule to identify low-risk patients with community-acquired pneumonia. New England Journal of Medicine 1997, 336(4):243-250.

21. Yandiola PP, Capelastegui A, Quintana J, Diez R, Gorordo I, Bilbao A, Zalacain R, Menendez R, Torres A: Prospective comparison of severity scores for predicting clinically relevant outcomes for patients hospitalized with community-acquired pneumonia. Chest 2009, 135(6):1572-1579.

22. Murray PR, Washington JA: Microscopic and baceriologic analysis of expectorated sputum. Mayo Clinic Proceedings 1975, 50(6):339-344.

23. Clinical and Laboratory Standards Institute: Methods for Dilution Antimicrobial Susceptiblity Tests for Bacteria That Grow Aerobically; Approved Standard-Eighth Edition. Clinical and Laboratory Standards Institute 2008, 29(2):M07-A08.

24. Kollef MH, Shorr A, Tabak YP, Gupta V, Liu LZ, Johannes RS: Epidemiology and outcomes of health-care-associated pneumonia: results from a large US database of culture-positive pneumonia. Chest 2005, 128(6):3854-3862.

25. Niederman MS: Making sense of scoring systems in community acquired pneumonia. Respirology 2009, 14(3):327-335.

26. Shindo Y, Sato S, Maruyama E, Ohashi T, Ogawa M, Imaizumi K, Hasegawa Y: Comparison of severity scoring systems A-DROP and CURB65 for community-acquired pneumonia. Respirology 2008, 13(5):731-735.

27. Shorr AF, Haque N, Taneja C, Zervos M, Lamerato L, Kothari S, Zilber S, Donabedian S, Perri MB, Spalding J, Oster G: Clinical and economic outcomes for patients with health care-associated Staphylococcus aureus pneumonia. J Clin Microbiol 2010, 48(9):3258-3262.

28. Lambert ML, Suetens C, Savey A, Palomar M, Hiesmayr M, Morales I, Agodi A, Frank U, Mertens K, Schumacher M, Wolkewitz M: Clinical outcomes of health-care-associated infections and antimicrobial resistance in patients admitted to European intensive-care units: a cohort study. Lancet Infect Dis 2011, 11(1):30-38

29. Kothe H, Bauer T, Marre R, Suttorp N, Welte T, Dalhoff K: Outcome of community-acquired pneumonia: influence of age, residence status and antimicrobial treatment. European Respiratory Journal 2008, 32(1):139-146.

30. Ruiz M, Ewig S, Marcos MA, Martinez JA, Arancibia F, Mensa J, Torres A: Etiology of community-acquired pneumonia: impact of age, comorbidity, and severity. American Journal of Respiratory and Critical Care Medicine 1999, 160(2):397-405.

\section{Pre-publication history}

The pre-publication history for this paper can be accessed here: http://www.biomedcentral.com/1471-2334/11/61/prepub

doi:10.1186/1471-2334-11-61

Cite this article as: Jung et al:: Healthcare-associated pneumonia among hospitalized patients in a Korean tertiary hospital. BMC Infectious Diseases 2011 11:61.

\section{Submit your next manuscript to BioMed Central and take full advantage of:}

- Convenient online submission

- Thorough peer review

- No space constraints or color figure charges

- Immediate publication on acceptance

- Inclusion in PubMed, CAS, Scopus and Google Scholar

- Research which is freely available for redistribution 